\title{
Retrofit em obras tombadas de infraestrutura urbana: o caso do Viaduto sobre a Galeria dos Estados
}

Retrofit on listed works of urban infrastructure: the case of the Viaduct over the Galeria dos Estados

Modernización de obras de infraestructura urbana: el caso del Viaducto sobre la Galería de los Estados

GALIMI, Stefano
PANTOJA, João da Costa ${ }^{2}$
BUZAR, Márcio Augusto Roma ${ }^{3}$
MACHADO, Paulo Robert Santos ${ }^{4}$
1Programa de Pós-Graduação - PPG-FAU, Universidade de Brasília, Brasília, Brasil. stefanogalimi.arch@gmail.com
ORCID: 0000-0002-3694-9133
2Programa de Pós-Graduação - PPG-FAU, Universidade de Brasília, Brasília, Brasil. joaocpantoja@gmail.com
ORCID: 0000-0002-0763-0107
3Programa de Pós-Graduação - PPG-FAU, Universidade de Brasília, Brasília, Brasil. marcio.buzar@gmail.com
ORCID: 0000-0002-1164-2784
4Departamento de Estradas e Rodagem - DER/DF, Superintendência de Obras, Brasília, Brasil.
robertmachado@hotmail.com
ORCID: 0000-0002-9793-0663




\title{
Resumo
}

A arquitetura monumental de Brasília, capital federal do Brasil, foi concebida pelos traços plásticos dos arquitetos Oscar Niemeyer e Lúcio Costa. Desde a sua fundação, a cidade atraiu o panorama arquitetônico internacional e foi designada, em 1987, como patrimônio cultural mundial pela UNESCO. O Retrofit representa uma pratica que garante a preservação de uma edificação, proporcionando uma nova reabilitação funcional. O presente trabalho aborda o caso do desabamento do Viaduto sobre a Galeria dos Estados, localizado no Eixo Rodoviário Sul - DF 002, uma das principais artérias viárias do plano piloto de Brasília. Analisadas as patologias e os mecanismos oriundos que levaram ao colapso estrutural parcial do antigo pilar e do tabuleiro protendido, foi avaliado o projeto de Retrofit que se deu por meio de pilares reestruturados com engrossamento do núcleo central e enrijecimento global da estrutura. Para entender o tipo de intervenção mais adequado para preservar o patrimônio, foram considerados os aspectos de desempenho e segurança estrutural, vida útil e linguagem arquitetônica, sem apresentação de modelos numéricos. O Retrofit adotado mostra como o valor patrimonial do viaduto foi respeitado sob uma ótica de acrescentar durabilidade à obra de arte e garantir a segurança dos utentes que o transitam.

Palavras-Chave: Viaduto sobre a Galeria dos Estados, Retrofit, Patrimônio Cultural, Segurança e Desempenho Estrutural, Brasília.

\begin{abstract}
The monumental architecture of Brasilia, the federal capital of Brazil, was conceived by the plastic features of the architects Oscar Niemeyer and Lúcio Costa. Since its foundation, the city has attracted the international architectural panorama and was designated, in 1987, as a world cultural heritage by UNESCO. The Retrofit represents a practice that guarantees the preservation of a certain building, providing new functional rehabilitation. This work deals with the case of the collapse of the Viaduct over the Gallery of States, located on the South Highway - DF 002, one of the main road arteries of the Brasilia pilot plan. After analyzing the pathologies and mechanisms that led to the partial structural collapse of the old pillar and prestressed board, the Retrofit project was evaluated through restructured pillars with thickening of the central core and global stiffening of the structure. In order to understand the most appropriate type of intervention to preserve heritage, aspects of performance and structural safety, useful life and architectural language were considered, without presentation of numerical models. The Retrofit adopted shows how the viaduct's patrimonial value was respected from the point of view of adding durability to the work of art and guaranteeing the safety of the users who transit it.
\end{abstract}

Key-Words: Viaduct over the Gallery of States, Retrofit, Cultural Heritage, Safety and Structural Performance, Brasilia.

\section{Resumen}

La arquitectura monumental de Brasilia, la capital federal de Brasil, fue concebida por las características plásticas de los arquitectos Oscar Niemeyer y Lucio Costa. Desde su fundación, la ciudad ha atraído el panorama arquitectónico internacional y fue designada, en 1987, como patrimonio cultural mundial por la UNESCO. La modernización representa una práctica que garantiza la preservación de un edificio, proporcionando una nueva rehabilitación funcional. Este trabajo aborda el caso del colapso del Viaducto sobre la Galería de los Estados, ubicada en el Eixo Rodoviário Sul - DF 002, una de las principales arterias viales del Plano Piloto de Brasilia. Después de analizar las patologías y los mecanismos que resultaron en el colapso estructural parcial del viejo pilar y el tablero pretensado, se evaluó el proyecto Retrofit por medio de pilares reestructurados con el engrosamiento del núcleo central y el endurecimiento global de la estructura. Para comprender el tipo de intervención más apropiado para preservar el patrimonio se consideraron los aspectos de rendimiento y seguridad estructural, vida útil y lenguaje arquitectónico, sin la presentación de modelos numéricos. La actualización adoptada muestra cómo se respetó el valor patrimonial del viaducto desde la perspectiva de agregar durabilidad a la obra de arte y garantizar la seguridad de los usuarios que la transitan.

Palabras clave: Viaducto sobre la Galería de los Estados, Retrofit, Patrimonio Cultural, Seguridad y Desempeño Estructural, Brasilia. 


\section{Introdução}

A criação de Brasília, na década de '60, foi caraterizada pela ruptura com a tradição da arquitetura. A busca de monumentalidade e eternidade na história, em contrapartida com a transitoriedade da vida, são as linhas guias e diretrizes da nova capital brasileira (Figura 1).

Figura 1: Eixo Monumental e Esplanada dos Ministérios, Brasília

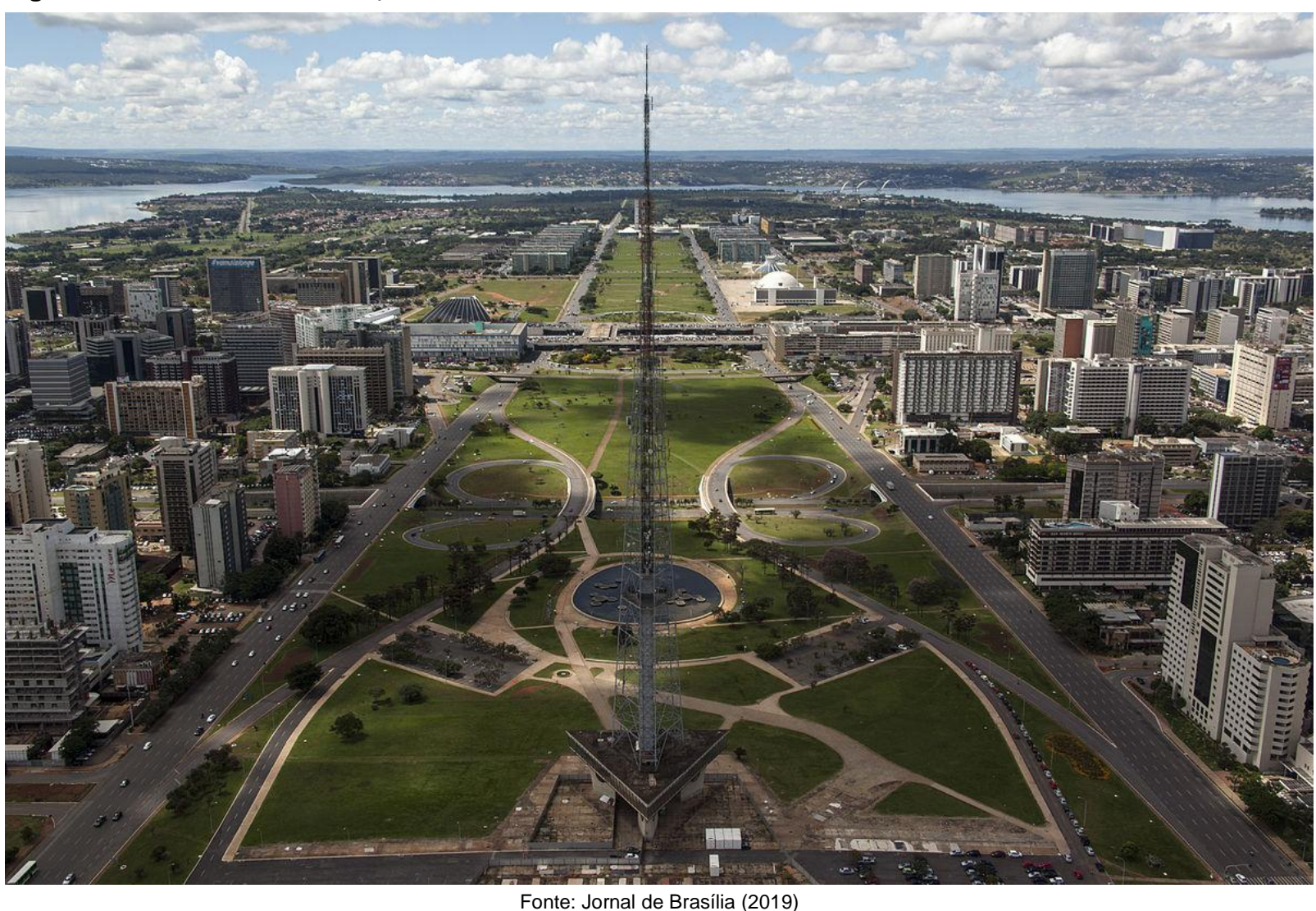

Lúcio Costa tinha uma sua própria concepção de monumentalidade, no sentido da expressão palpável do espírito, da essência e das questões imateriais do projeto da cidade nova. A implantação monumental de Brasília na região Centro-Oeste do país, se articula em dois eixos principais que se cruzam em ângulo reto, sendo o eixo rodoviário que desce para o lago Paranoá e o Monumental, que cruza a cidade inteira de norte a sul. A partir desses dois traçados principais, a cidade se expandiu (Figura 2). 
Figura 2 - 3: Esboço do Plano Piloto de Brasília por Lúcio Costa em 1956

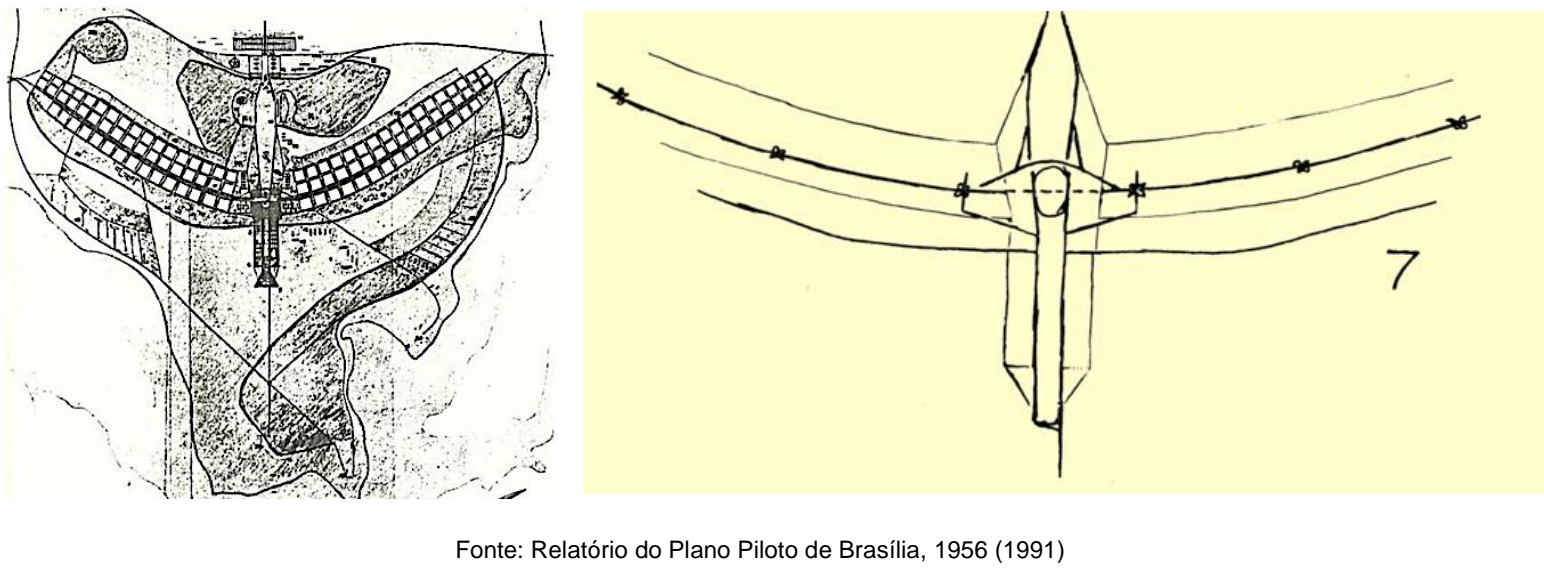

O modernismo internacional, concebido com o objetivo de manifestar o otimismo de uma nova era através da arquitetura, a mais alta forma de expressão artística, fundamentou uma outra compreensão das qualidades espaciais, utilizando inovações tecnológicas e estruturais (MACDONALD, 2007). No panorama brasileiro, a arquitetura moderna de Brasília, autêntica, assinada pelos arquitetos Oscar Niemeyer e Lúcio Costa, se consagrou patrimônio histórico e artístico nacional pelo Instituto do Patrimônio Histórico e Artístico Nacional - IPHAN, criado no final da década dos anos 30' (BISPO, 2014). As arquiteturas de Brasília possuem muitas realizações importantes na área de engenharia das estruturas, sendo muitas delas originais e inovadoras para a época da execução. O caso do Viaduto sobre a Galeria dos Estados (Figura 3) representa um firme ponto de partida para as futuras operações de manutenção do patrimônio de capital brasileira. Cabe ressaltar que, o viaduto, localizado no Eixão Sul - via concebida sob a visão rodoviarista (COSTA, 1991) destinada para a realização de grande parte dos deslocamentos Sul-Norte e vice-versa, deve ser considerado uma das principais artérias viárias de Brasília tanto em termos de importância no que tange à estrutura urbana (HOLANDA, 2002; BARROS, 2006; MEDEIROS, 2013), quanto em termos de volume veicular (BARROS, 2006). 
Figura 4: Colapso do Viaduto sobre a Galeria dos Estados

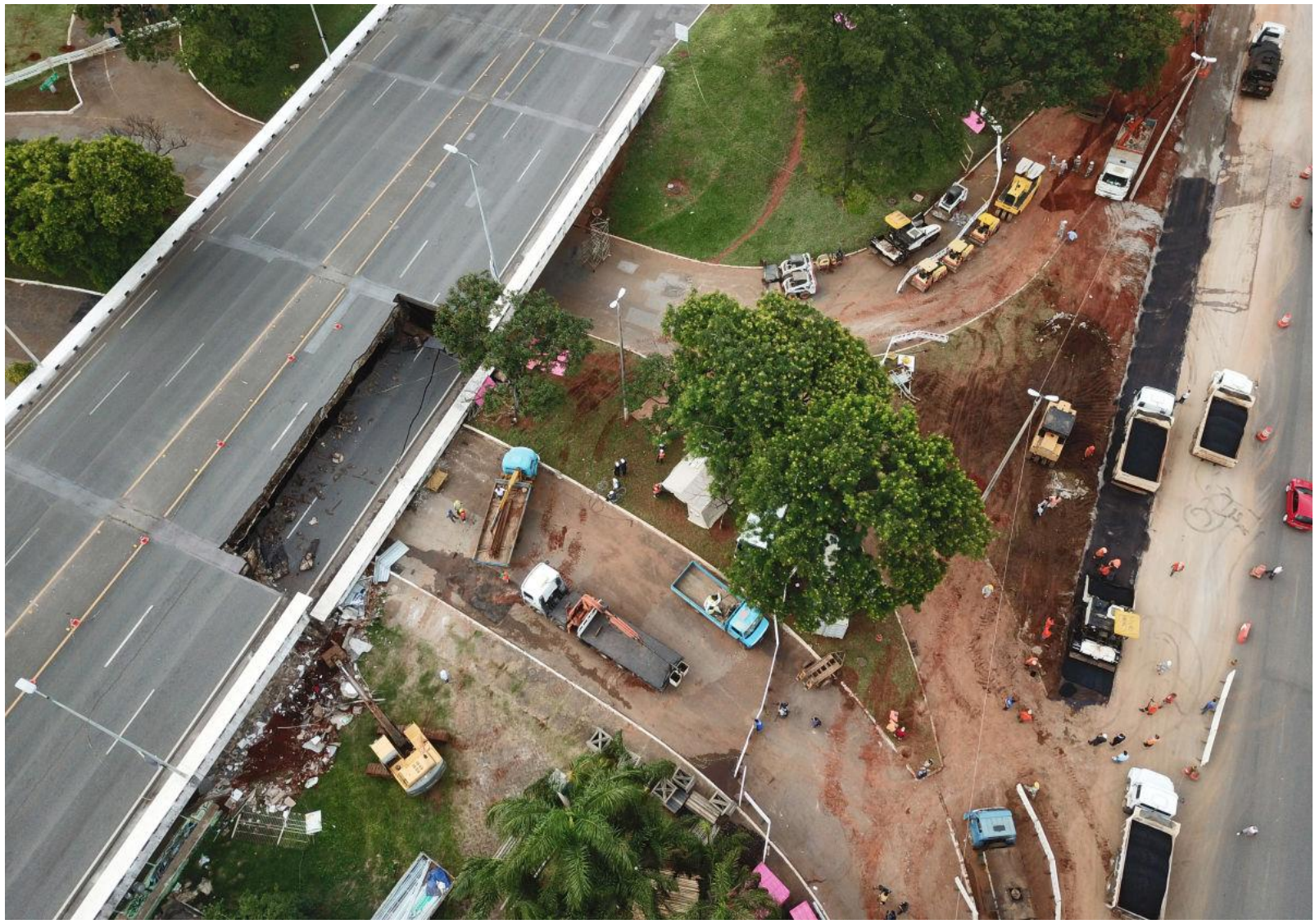

Fonte: Correio Brasiliense (2018)

Ligado a esse conceito, a arquitetura deve preservar o papel de integridade, segurança e desempenho da obra através de intervenções atentas. O termo Retrofit, aplicado à construção civil, se refere às práticas empregadas para requalificação funcional de edificações existentes que, devido ao tempo ou falta de manutenção, se tornaram obsoletas. No projeto de Retrofit, a estrutura deve ser calculada de modo que seja segura e durável, levando em consideração tanto a manutenção periódica pósmodernização quanto o respeito pelo meio ambiente (UEDA e SHIMOMURA, 1999). De acordo com Barrientos (2004), o Retrofit, considerado como o "renascimento no lugar da destruição", é aquele conjunto de ações voltadas para reabilitação tecnológica de um edifício. Este conceito, corroborado pelo Vale (2006), determina que a principal finalidade do Retrofit seja o reestabelecimento do antigo desempenho perdido ao longo da vida útil. Portanto, uma edificação que passou por este processo deve propiciar aos seus usuários uma melhor qualidade de vida (MORAES e QUELHAS, 2012). O Viaduto sobre a Galeria dos Estados foi concebido juntamente ao projeto da cidade e, pela tecnologia da protensão, representa um avanço do ponto de vista estrutural e construtivo. Devido às circunstancias vividas nos últimos tempos na capital brasileira, a pergunta sobre intervenção, manutenção e preservação do patrimônio cultural precisa de uma resposta adequada, a partir de uma contextualização teórica sobre o panorama das discussões acerca da prática preservacionista, voltada para as obras modernistas de infraestrutura urbana. $O$ trabalho tem como objetivo apresentar as causas do colapso parcial da estrutura e mostrar o projeto de Retrofit executado pelo Departamento de estradas de rodagem do Distrito Federal (DER/DF) e a NOVACAP, fornecendo conclusões/recomendações que possam se estender às obras de infraestrutura urbana tombada. Em particular, são retratadas as diferenças comportamentais entre as condições físicas e mecânicas do viaduto antes do desabamento parcial e depois do projeto de Retrofit, sem apresentação de modelos estruturais gerados via analise de elementos finitos. 


\section{O Viaduto}

A importância estruturadora do Viaduto sobre a Galeria dos Estados centraliza a ideia da circulação viária da cidade, permitindo aos usuários de Brasília rápido acesso aos extremos da capital. Acontecido em 6 de fevereiro de 2018, por volta das 11h45, o desabamento paralisou o fluxo de trânsito nessa porção nodal de Brasília. A infraestrutura urbana foi concebida e construída entre dezembro de 1959 e fevereiro de 1960 pelo arquiteto Lúcio Costa e o engenheiro Sérgio Marques. Localizado na parte sul do Eixo Rodoviário de Brasília (DF-002), o viaduto é composto por seis faixas de trânsito e uma faixa presidencial no centro, totalizando $28 \mathrm{~m}$ de largura e aproximadamente $192 \mathrm{~m}$ de extensão (Figuras 5 e 6 ).

Figura 5 - 6: Localização do Viaduto sobre a Galeria dos Estados (1957) e Galeria dos Estados

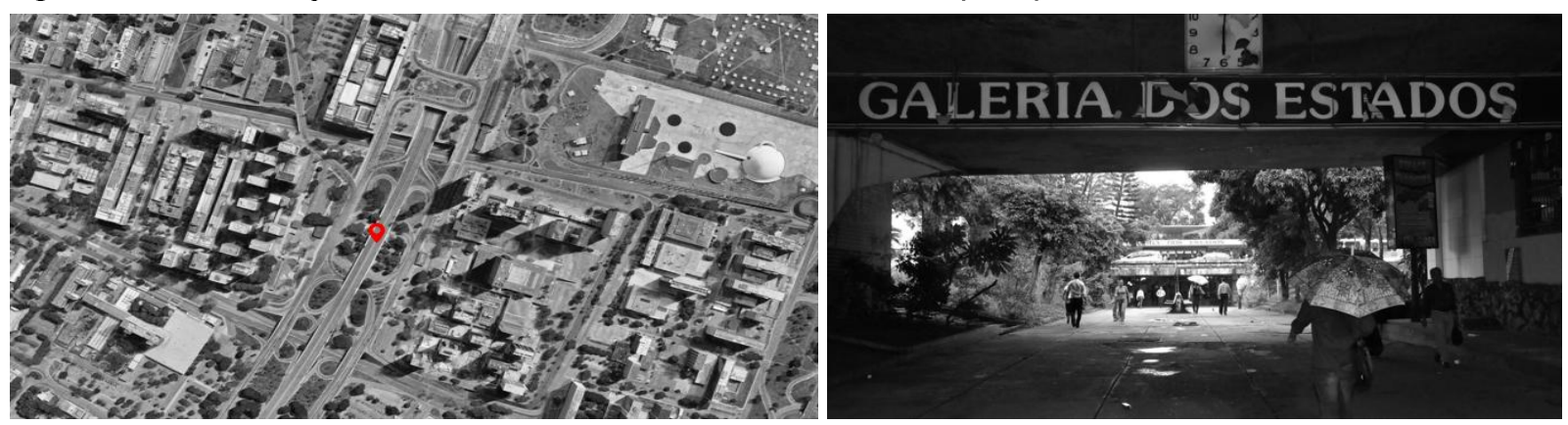

Fonte: Google Earth (2019), Agência Brasília (2013)

A estrutura original do viaduto, composta por 8 tabuleiros de lajes alveolares protendidas, 7 pilares em concreto protendido e 2 cortinas de contenção, foi afetada por patologias que, sem a devida manutenção periódica e/o extraordinária, levaram ao colapso estrutural (Figura 7). Na nota 7, referente ao Relatório do Lúcio Costa sobre Brasília, emerge a priorização desse eixo viário da capital:

"Desse modo e com a introdução de três trevos completos em cada ramo do eixo rodoviário e outras tantas passagens de nível inferior, o tráfego de automóveis e ônibus se processa tanto na parte central quanto nos setores residenciais sem qualquer cruzamento".

(COSTA, 1991)

Figura 7: Formato original do pilar P7, Viaduto sobre a Galeria dos Estados
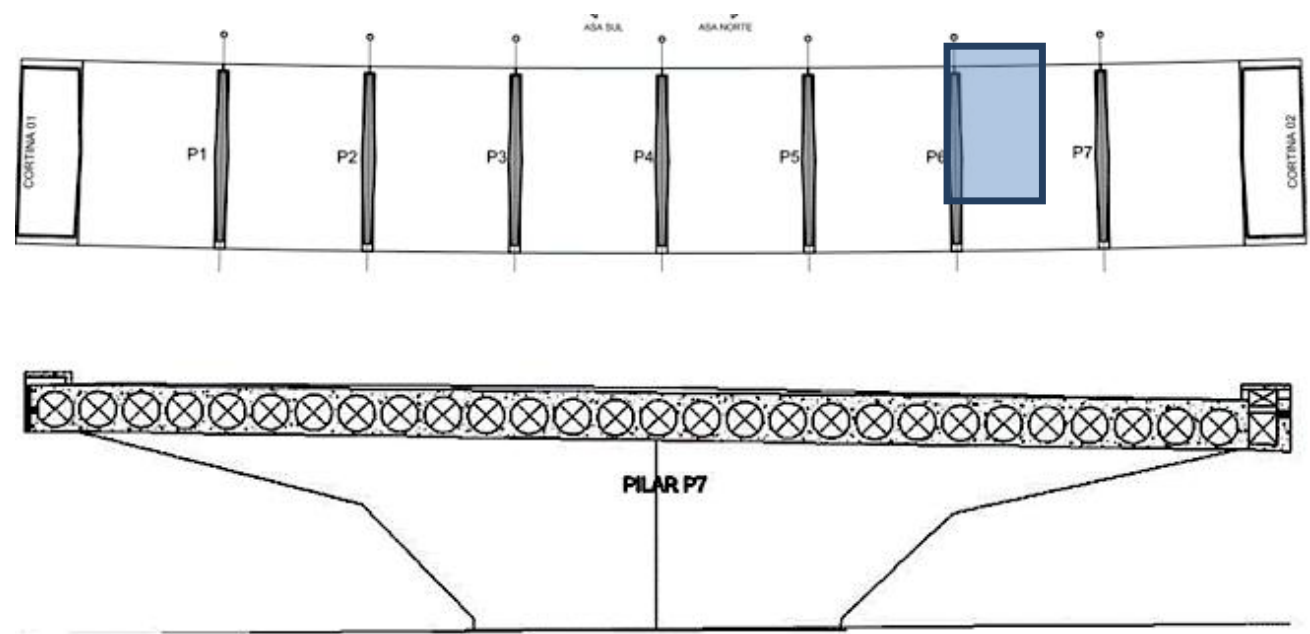

Fonte: Laudo de vistoria técnica da NOVACAP (2018) 


\section{Metodologia de avaliação do processo de Retrofit}

Os projetos de Retrofit, muitas vezes utilizados para preservar o patrimônio cultural, devem analisar em primeira instancia as características originais da construção, as mudanças físicas que ocorreram durante o tempo, os fenômenos de danos causados por transformações antrópicas e o envelhecimento dos materiais de construção (FORMISANO e MILANI, 2019). No Brasil, não existe uma norma que regulamente essa pratica, que, pela ABNT NBR 15575:2013, é definida como atualização da edificação por meio de incorporações tecnológicas que visem aumentar a vida útil do bem patrimonial (NEGREIROS, 2018). Portanto, torna-se necessário refinar as técnicas de análise para intervenção em obras tombadas em relação ao seu impacto na sociedade atual. O conhecimento pode ser alcançado por meio de diferentes níveis de aprofundamento em termos de operações de pesquisa in loco, pesquisas históricas e investigações experimentais. $O$ estudo das características da construção visa definir um modelo que permita uma interpretação qualitativa e quantitativa do sistema estrutural para obter a melhor proposta de intervenção. O caso do Viaduto sobre a Galeria dos Estados se caracteriza como uma obra de arte da infraestrutura urbana e não é considerado uma edificação convencional. A elaboração da metodologia deu-se em duas fases distintas. Durante a primeira, de inspeção visual in loco, foi avaliado o desempenho do viaduto após colapso, mostrando as patologias existentes na estrutura, os agentes de deterioração dos materiais que os levaram até o fim da própria vida útil e o comportamento físico dos elementos estruturais. Este ultimo item, corroborado por resultados de ensaios de resistência à compressão axial e tração, revela as dinâmicas que levaram ao acidente. $\mathrm{Na}$ segunda etapa do trabalho, foi feita uma avaliação da solução de Retrofit adotado, mostrando as vantagens que foram implementadas ao conjunto.

\subsection{Desempenho estrutural comprometido pelas patologias decorrentes}

O processo de degradação em uma estrutura submetida à diferentes esforços e solicitações, além das ações ambientais variáveis, é determinada por diferentes fatores quais a baixa qualidade dos materiais, problemas na fase de projeto, de execução de obra e a falta de manutenção periódica. A procura da durabilidade de uma estrutura, devido ao aumento da qualidade de vida dos usuários e à concorrência sempre maior do mercado, é uma tendência que domina o panorama internacional atual da construção civil. A preservação patrimonial do Viaduto sobre a Galeria dos Estados foi garantida por meio de uma analise empírica sobre o status das condições nas quais versava e, por meio desse trabalho, serão expostas as causas que geraram o desabamento da alça do pilar e do trecho do tabuleiro alveolar. Os três principais agentes que favoreceram a formação das patologias que afetaram a infraestrutura urbana foram a temperatura, a água e o dióxido de carbono.

\subsubsection{Temperatura, Água e Dióxido de Carbono (CO2) como agentes de deterioração}

As estruturas de concreto, assim como outras, estão sujeitas à dilatação e à contração devido à variação de temperatura. Parte dessa retração de origem térmica fica restringida por vários motivos (própria rigidez interna do concreto e vinculação da estrutura no solo), gerando tensões de tração (Figuras 8 e 9) que ultrapassaram a capacidade de resistência mecânica do concreto, ocasionando fissuras. Devido também à existência de infiltrações de água, ocorreu um processo de dissolução e transporte da cal hidratada presente no concreto, chamado de lixiviação. Esse produto lixiviado, ao interagir com o dióxido de carbono presente no ar, resultou na precipitação de crostas brancas de carbonato de cálcio na superfície, gerando eflorescência. As consequências ocorridas resultaram na redução da resistência mecânica do material e permitiram a entrada de gases e líquidos agressivos às armaduras e ao próprio concreto. As figuras 10 e 11 mostram claramente a presença de fissuras compridas ao longo do tabuleiro do viaduto. É importante salientar que na época em que foi projetado o viaduto a norma técnica vigente era a segunda versão da NB1/1940 - Norma para o cálculo e execução de estruturas de concreto. Nessa norma ainda não havia o entendimento técnico de desempenho da estrutura levando-se em conta os aspectos de durabilidade. Tanto é verdade que 
nessa época se permitia construções com cobrimentos mínimos para as seções de concreto. Em lajes esse cobrimento chegava a $5 \mathrm{~mm}$. Na norma vigente esse cobrimento mínimo passou a ser $25 \mathrm{~mm}$.

Figura 8 - 9: Fissuras ocasionadas pela retração do concreto

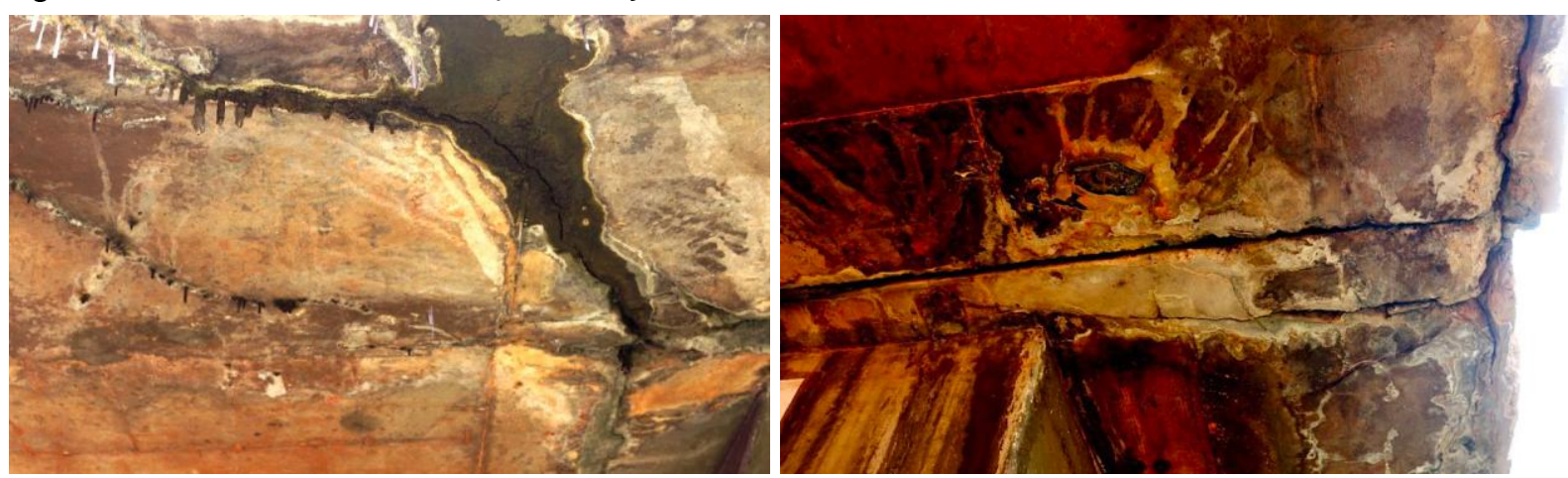

Fonte: Laudo de vistoria técnica da NOVACAP (2018)

Figura 10 - 11: Fissuras no trecho do tabuleiro
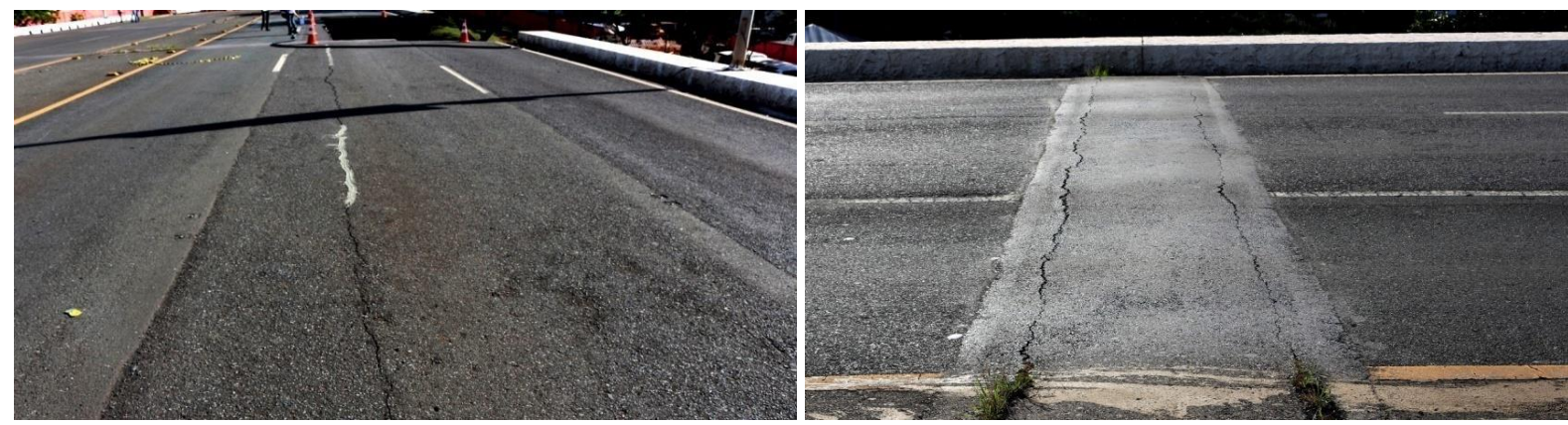

Fonte: RELATÓRIO TÉCNICO Dept. ENC/UnB 001 (2018)

Figura 12: Fissuras ocorridas no pilar P7 antes do colapso estrutural

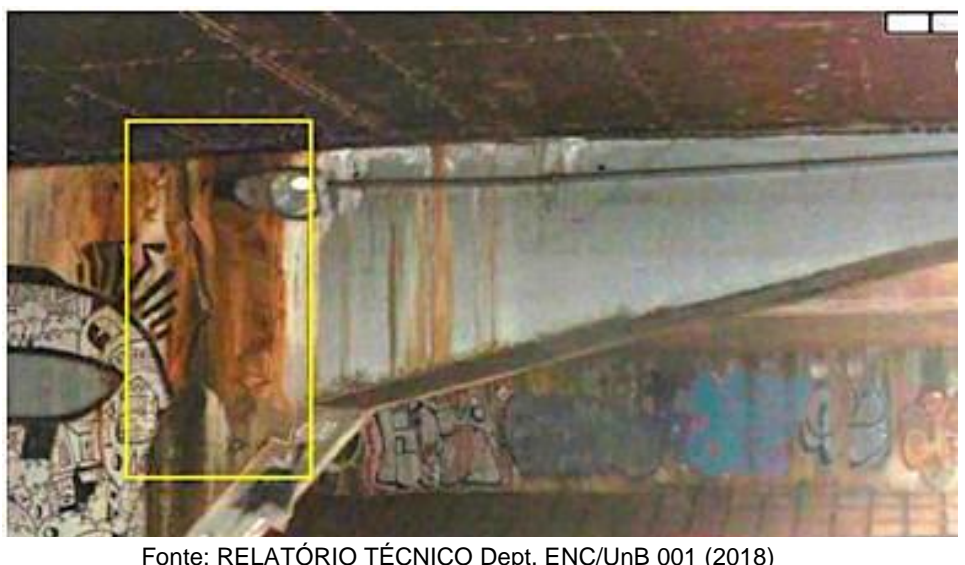

O mecanismo de infiltração da água por um longo período de tempo, cerca de 40anos, na ligação entre o tabuleiro e o pilar, devido à presença de fissuras de contração nessa região, já indicava a necessidade de intervenção no local em que ocorreu a ruptura do trecho do tabuleiro protendido do Viaduto sobre a Galeria dos Estados (coincidente ao Pilar P7, Figura 12). Devido também à percolação da água através das trincas existentes por um período de tempo prolongado, houve corrosão das armaduras em elevado grau e consequente fenômeno de despassivação das armaduras, como mostra a Figura 13. Dessa forma, por causa da corrosão das armaduras ativas do pilar P7, o elemento estrutural não foi capaz de suportar o carregamento dinâmico dos veículos e veio ao estado de colapso, sobrecarregando a alça em balanço do pilar P6, que também desabou. As cargas devido ao trem tipo na época também eram menores do que as atuais. Por exemplo, se tem trafegando naquela região ônibus biarticulado. 
Figura 13: Corrosão das cordoalhas protendidas

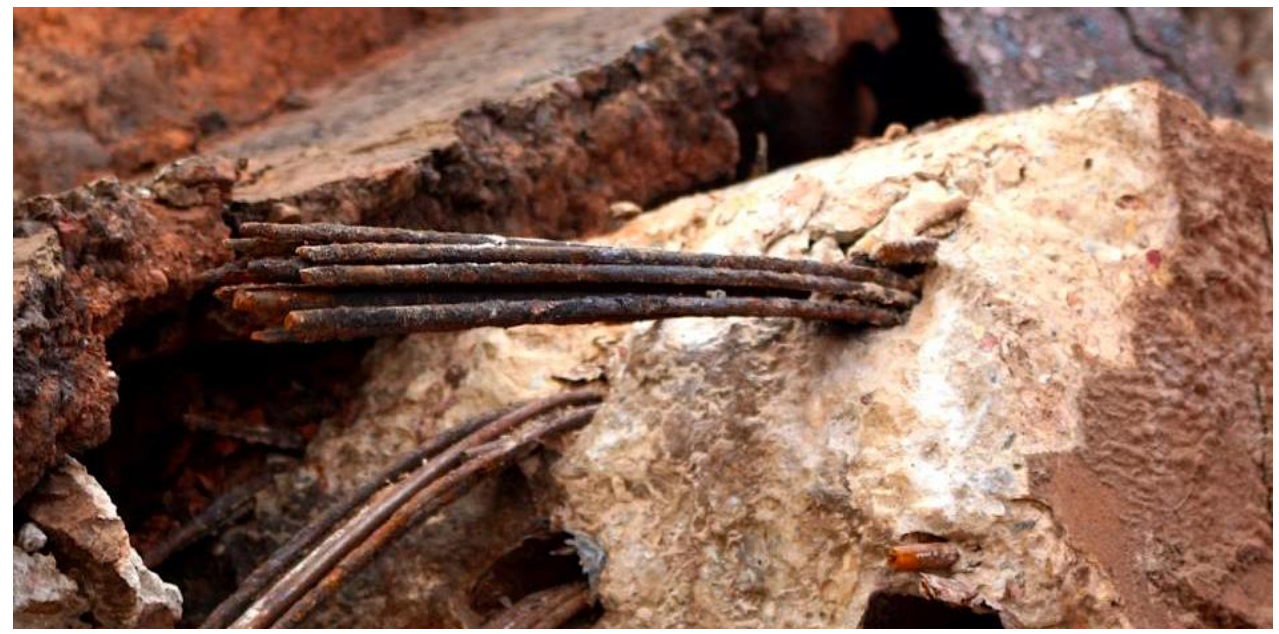

Fonte: RELATÓRIO TÉCNICO Dept. ENC/UnB 001 (2018)

O concreto produzido com cimento Portland comum resulta em um material bastante alcalino e não favorece o desencadeamento de reações de corrosão nas armaduras. Com a penetração de ar nos poros do concreto, em meio úmido, na estrutura do viaduto ocorreram reações químicas que deram origem ao carbonato de cálcio e carbonato de magnésio (carbonatação, Figura 14). A carbonatação redundou em uma acentuada queda no $\mathrm{pH}$ do concreto, com consequente redução na proteção das armaduras, gerando despassivação das mesmas. Os ensaios foram realizados de acordo com as prescrições da ABNT NBR 7680:2015 e os corpos de prova extraídos dos pilares P6 e P7, que sofreram o colapso estrutural, apresentaram uma boa resistência característica media (fck) à compressão de, respectivamente, 30,80 Mpa e 43,55 Mpa.

Figura 14: Extração do corpo de prova mostrando carbonatação

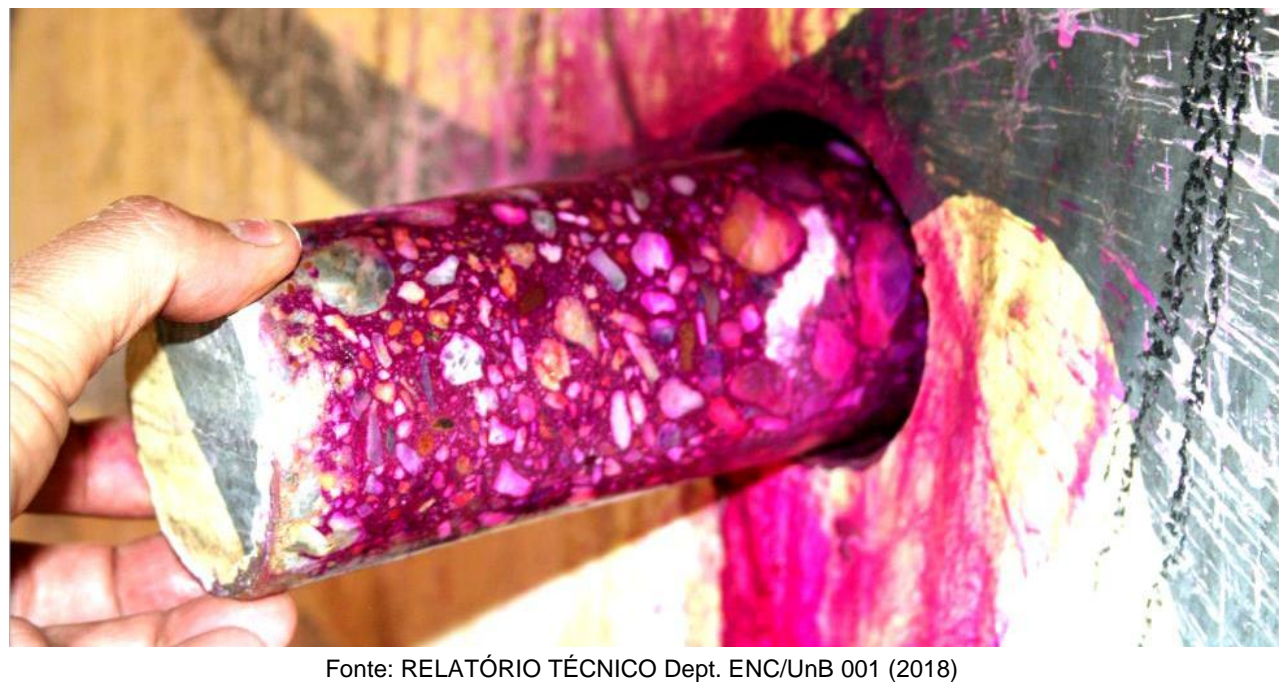

\subsection{Resultado dos ensaios}

No que tange ao ensaio de metalografia do aço, como demostra o gráfico das Figuras 15 e 16, o Departamento de Engenharia Civil da Universidade de Brasília (ENC/UnB) observou em uma das amostras uma diminuição da seção transversal na ordem de $67 \%$. 
Figura 15 - 16: Ensaio tensão/deformação das armaduras metálicas

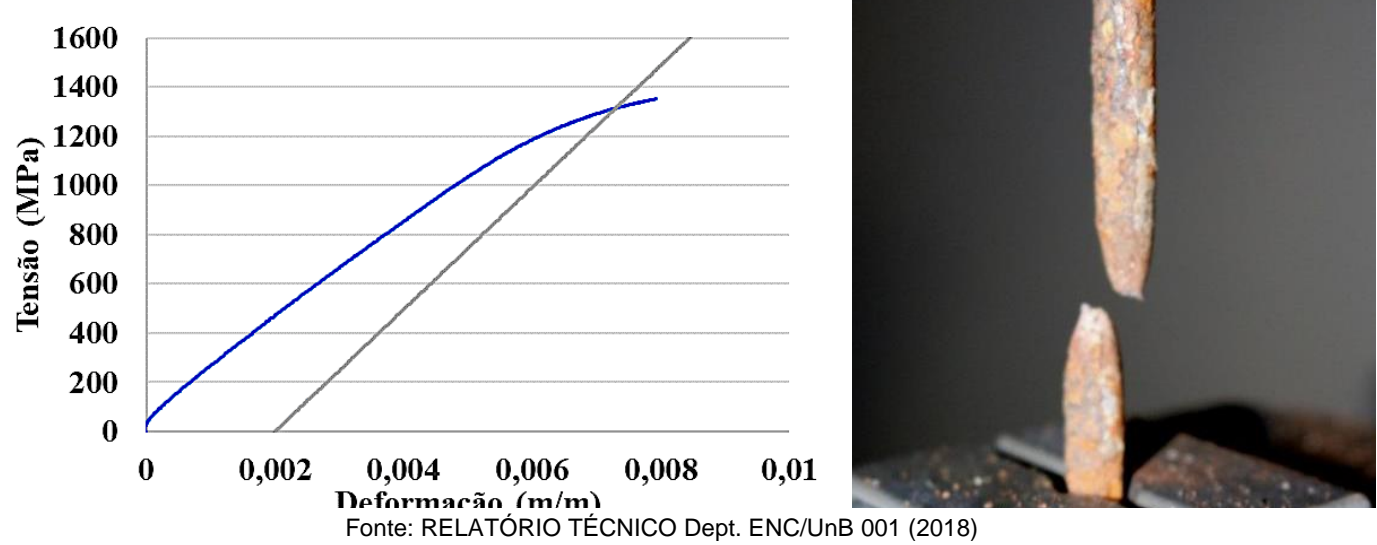

A norma ABNT NBR 6892:2012 regulamentou os ensaios de tração das barras constituintes as armaduras passivas, do tipo CA-32. Após uma análise aprofundada, foi detectado um alto nível de corrosão e tensão de escoamento (fy) insatisfatória. O material aço da armadura ativa de protensão do tipo CP-150 RN, apresentou um importante nível de corrosão e foi detectada uma diminuição da seção transversal na ordem de $50 \%$. O material concreto apresentou uma resistência à compressão da amostra 001 (Pilar P7) de 43,8 Mpa e da amostra 003 (Pilar P6) em 27,9 Mpa. Os parâmetros de resistência do concreto, portanto, indicaram que a qualidade do concreto utilizado foi absolutamente preservada durante a fase de execução do viaduto (Figura 17).

Figura 17: Corpos de prova 001 e 003

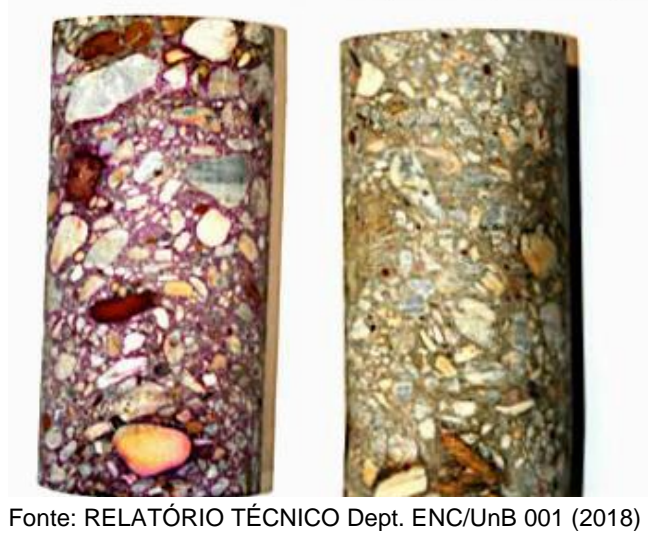

\section{Projeto de Retrofit do Viaduto sobre a Galeria dos Estados}

Executado pelos órgãos da DER/DF e a NOVACAP, o projeto de Retrofit aplicado à obra do Viaduto sobre a Galeria dos Estados visa em garantir mais segurança para os usuários, uma durabilidade da vida útil maior, sem alterar a harmonia das proporções dos pilares em formato "Asa Delta" que foram projetados e previstos pelo Lucio Costa.

A fim de propor soluções relativas à reconstrução/funcionalização do viaduto, foi optado pela demolição parcial da estrutura. Antes das primeiras fases do projeto de Retrofit, foi realizado um sistema de escoramento (cimbramento) permanente em todos os painéis constituintes o tabuleiro protendido e, consequentemente, foram desprezadas as contribuições de resistência das alças em balanço dos pilares, de forma a garantir uma maior segurança para a infraestrutura. Segundo o novo projeto, disponibilizado pela DER/DF e NOVACAP, foram executados novos blocos e fundações adicionais para o apoio dos novos pilares, de forma a diminuir os balanços laterais dos mesmos 
(Figuras 18 e 19).

Figura 18 - 19: Novas fundações e reforço do pilar original
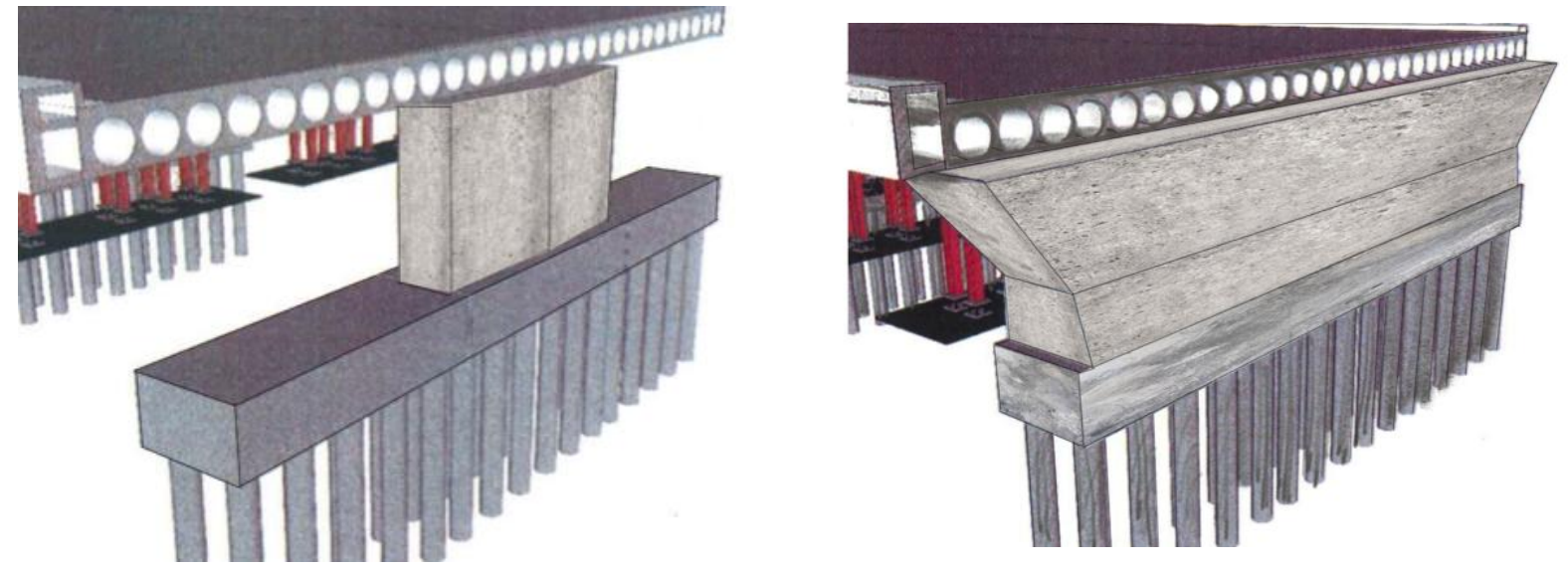

Fonte: Proposta de recuperação do Viaduto sobre a Galeria dos estados da DER/DF e NOVACAP (2018)

O projeto de retrofit do viaduto, aprovado pelo Iphan é de autoria do arquiteto Francisco Junior, onde o mesmo projetou novos pilares do Viaduto sobre a Galeria dos Estados, como se observa nas Figuras 20 e 21, constam em um engrossamento do núcleo central dos pilares originais, servindo de apoio para as lajes existentes. O projeto original do viaduto não permitia a inspeção dos aparelhos de apoio. Sendo que os mesmos foram reposicionados de forma a permitir tanto a troca como sua inspeção.

Figura 20 - 21: Projeto de novas fundações e reforço do pilar original
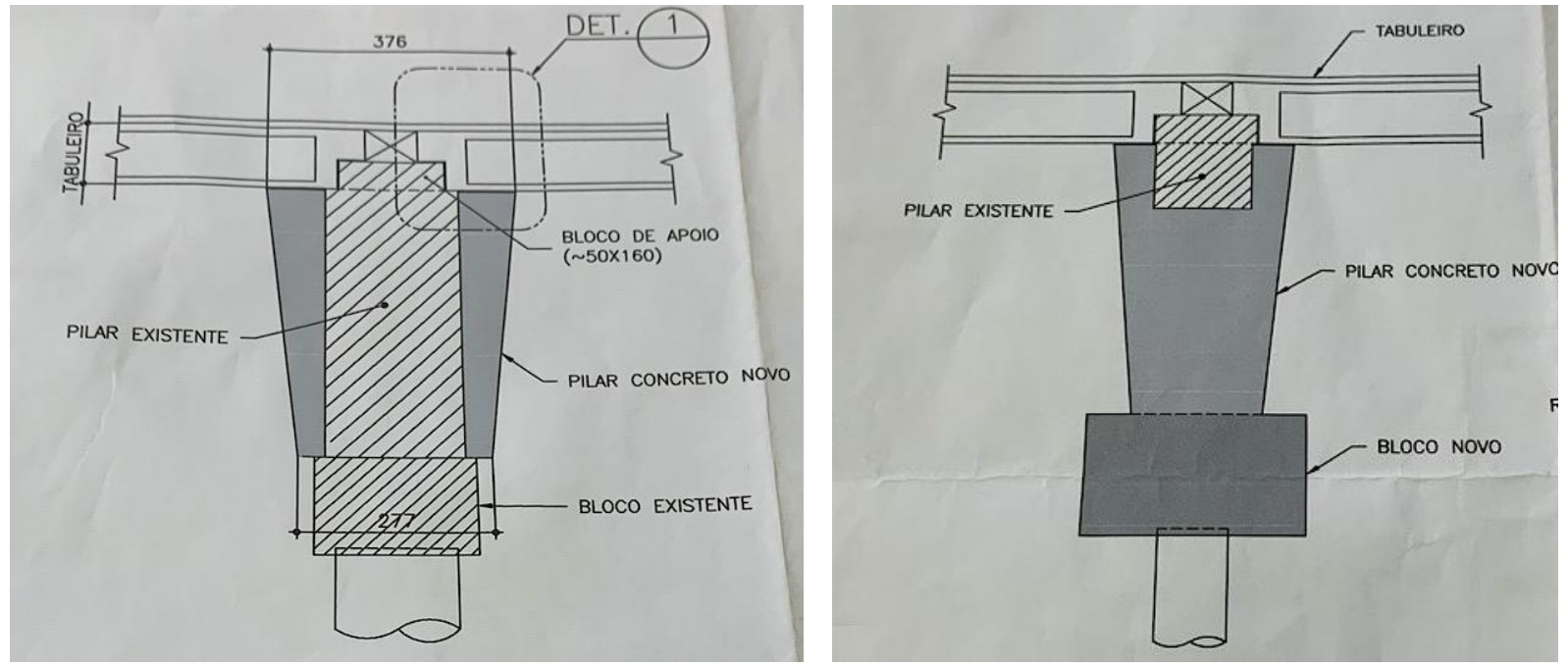

Fonte: Autoral (2019) 
Figura 22: Perfil do novo pilar

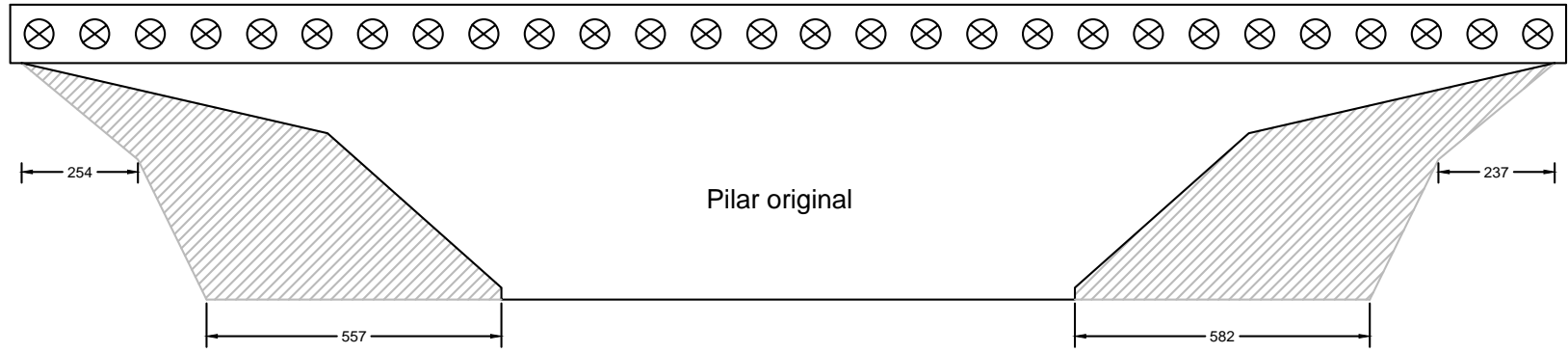

Aumento de seção para o novo pilar

Fonte: Autoral (2019)

Aumentada a seção transversal do pilar para $376 \mathrm{~cm}$ no ponto de contato com o tabuleiro superior (Figura 22) e a seção longitudinal, conforme a Figura 23, o novo aspecto estético do pilar se apresenta com uma volumetria mais robusta, demarcando um forte caráter de durabilidade e segurança para a obra de infraestrutura urbana. O detalhe arquitetônico dos balanços "Asa Delta" foi mantido, preservando o partido original do arquiteto Lúcio Costa (Figura 24).

Figura 23: Novo pilar após projeto de Retrofit

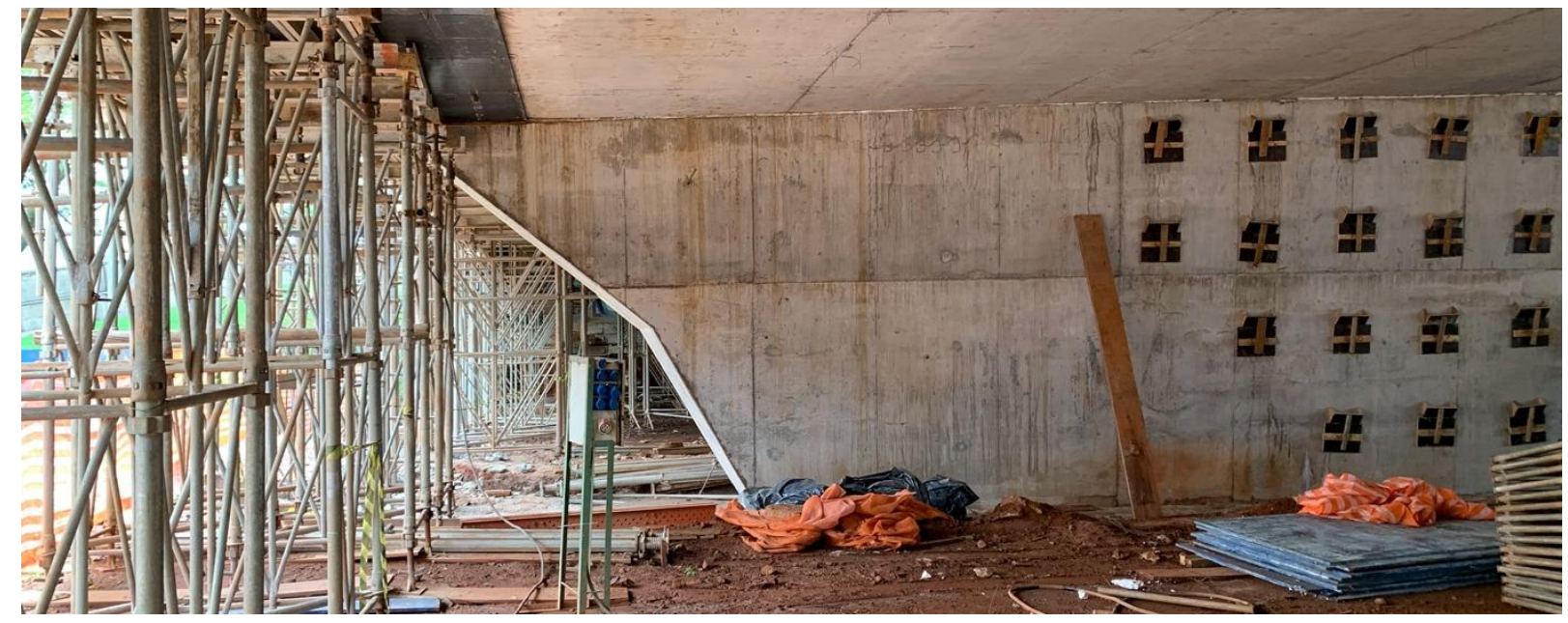

Fonte: Autoral (2019)

Figura 24: Novo pilar após projeto de Retrofit

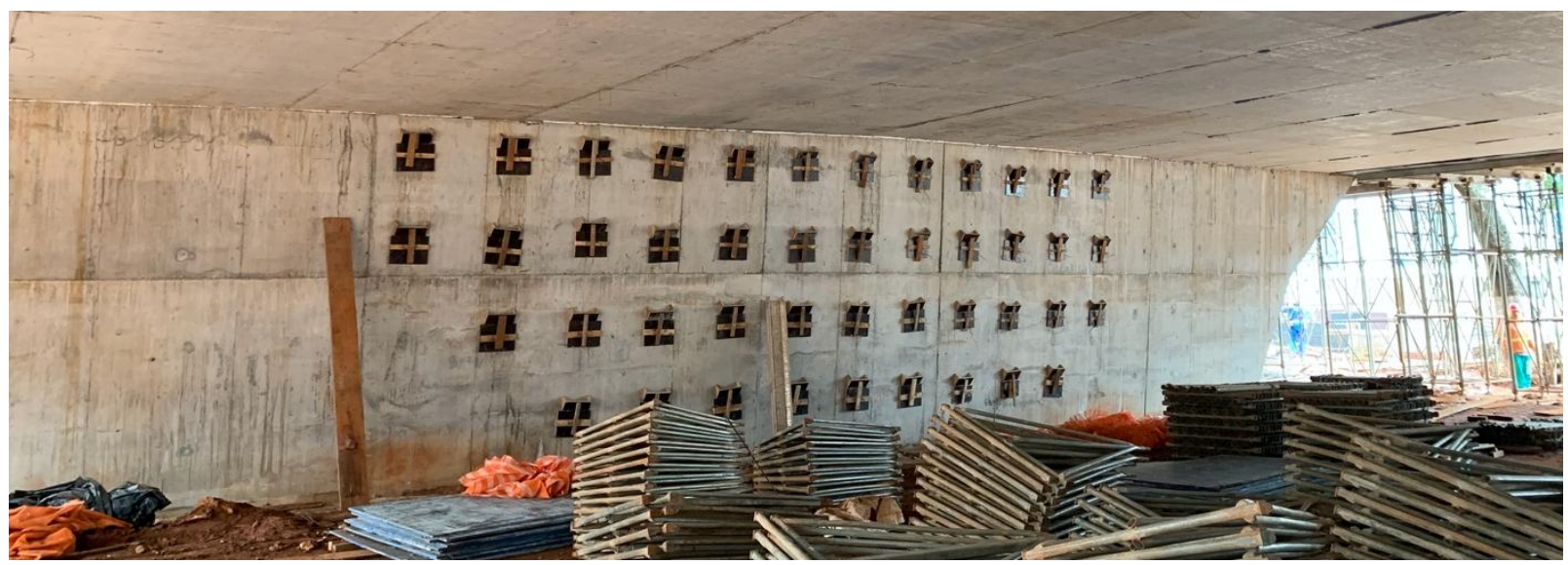

Fonte: Autoral (2019)

Após a restruturação do sistema de apoio, foram demolidas e reconstruídas as lajes alveolares protendidas entre os pilares P6 e P7. O concreto permanecente na cabeça das lajes foi retirado de 
forma a permitir a recuperação de todos os trechos da laje. Em adição a essa medida, foi descartada toda a armadura existente nos painéis protendidos, com a execução de nova armadura de protensão, garantindo a durabilidade do conjunto das lajes do tabuleiro e proporcionando um nível maior de segurança e desempenho. Novas vigas de concreto foram lançadas entre os painéis alveolares, aumentando a rigidez estrutural e mantendo a concepção estrutural original do Viaduto sobre a Galeria dos Estados. As Figuras 25 e 26 como também as Figuras 27 e 28 mostram as armaduras das longarinas que irão ser concretadas em seguida.

Figura 25 - 26: Armaduras das longarinas de concreto

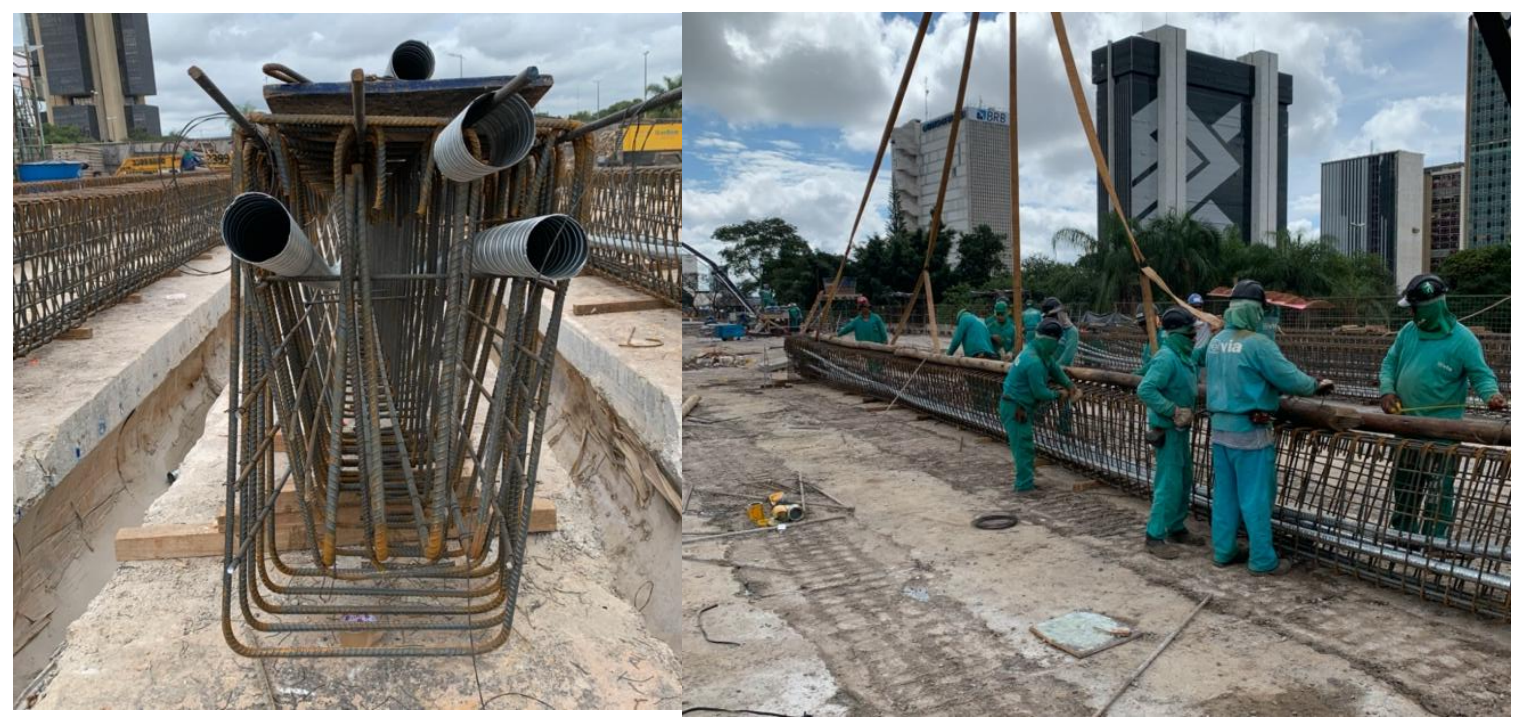

Fonte: Autoral (2019) 
Figura 27 - 28: Nova armadura de protensão e reconstituição das galerias de águas pluviais

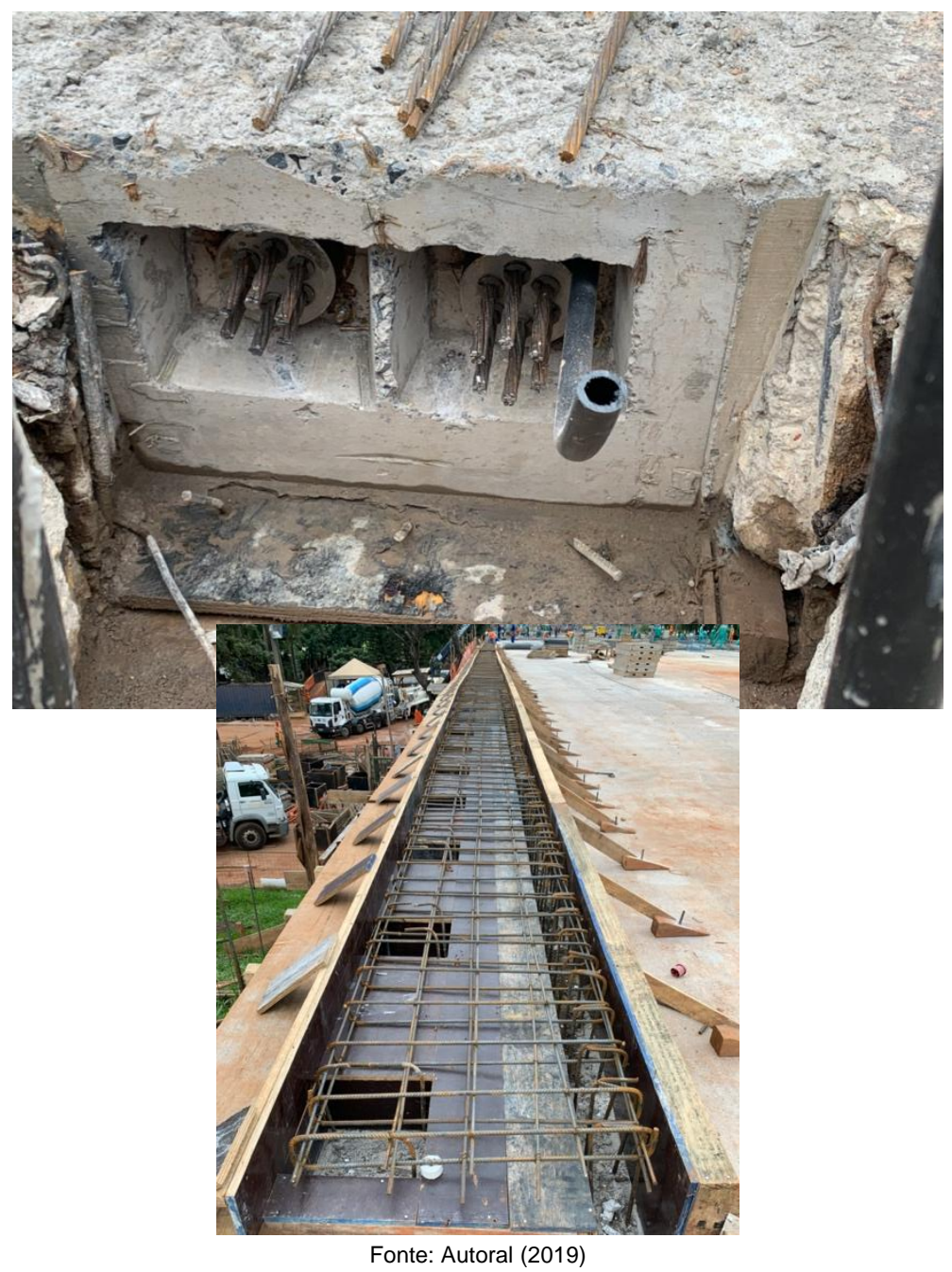

Como medidas adicionais, foram colocados buzinotes, nos tabuleiros do viaduto, para se fazer a drenagem direta das águas de chuva e também foram construídas lajes de consolidação sobre toda a extensão do tabuleiro, em seguida foram impermeabilizadas as lajes existentes do viaduto. De forma a corrigir uma falha no projeto original, onde o mesmo, por meio de galerias, conduzia para os pilares de forma inapropriada as águas de chuva possibilitando ainda mais a concentração de água nos pilares e acelerando o processo corrosivo nos mesmos. (Figuras 29, 30). 
Figura 29 - 30: Canteiro pronto para concretagem do capeamento final do tabuleiro do viaduto

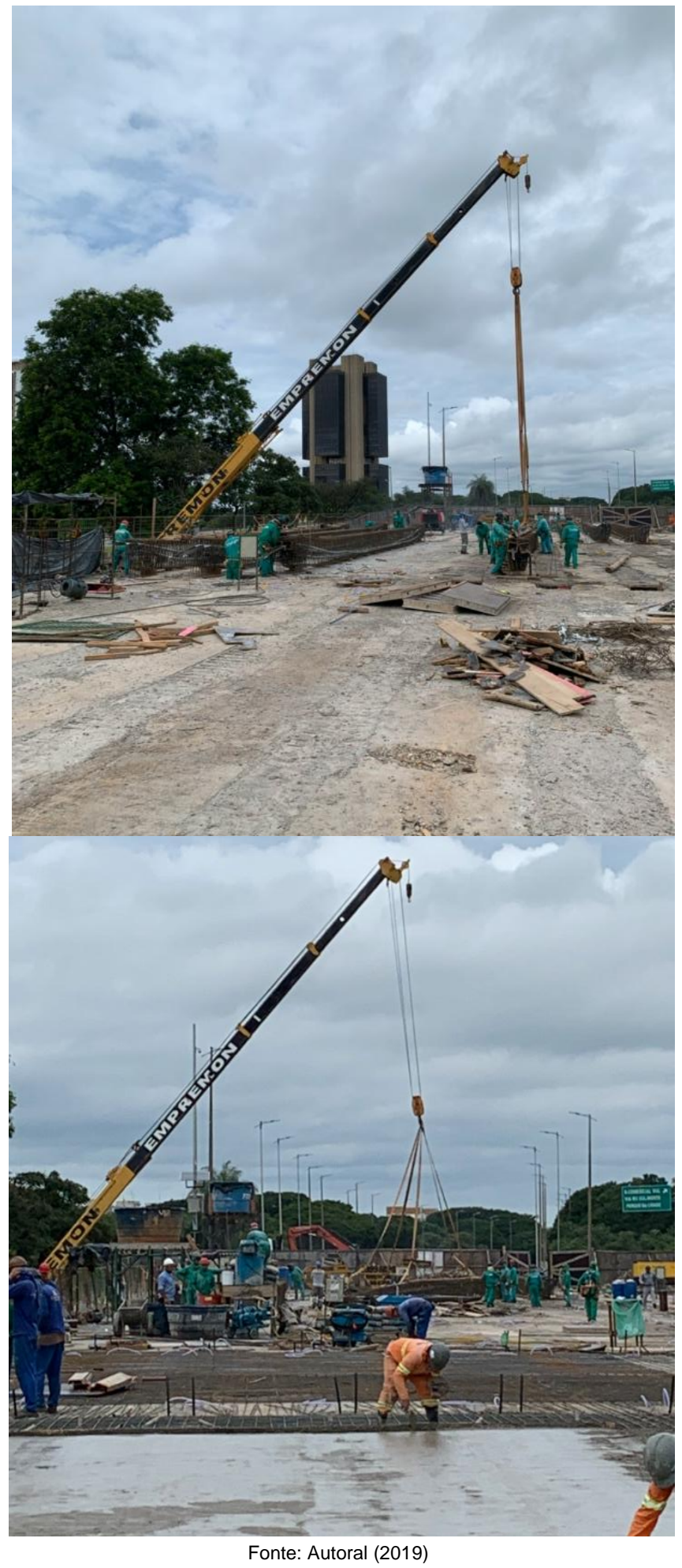

\section{Conclusões}

O caso do viaduto despertou um novo olhar para discutir sobre preservação do patrimônio e do ambiente construído. Tratando-se de uma obra prima, seja pela sua importância histórica, seja pela funcional, as instancias para elaborar considerações de intervenção devem passar por uma analise critica bastante delicada. O Viaduto sobre a Galeria dos Estados, obra da arquitetura modernista 
brasileira, deve ser classificado como monumento e, portanto, como objeto passível de restauração e nova função estrutural. A autenticidade do viaduto, associada à verdadeira obra de arte da criatividade humana, realça a importância desse trecho viário através da história de Brasília e dos brasilienses. Esse entendimento, ajuda na formulação de teorias e práticas preservacionistas sobre o objeto arquitetônico em questão. O presente artigo avaliou as diferenças entre as condições físicas e mecânicas do Viaduto sobre a Galeria dos Estados em duas fases distintas da própria vida útil. Após o desabamento parcial, a funcionalidade da infraestrutura se tornou obsoleta, sendo precisa uma rápida resposta dos órgãos governamentais. Em particular, o projeto de Retrofit executado pela DER/DF e NOVACAP, demonstrou que é possível retomar a linguagem arquitetônica originaria do pensamento do arquiteto Lúcio Costa, através de intervenções adequadas que proporcionem mais segurança para os utentes da infraestrutura urbana e maior vida útil dos materiais. $O$ aumento das fundações junto ao engrossamento dos pilares, que mantiveram o formato de "Asa Delta", foram implementados pelos projetistas para que o conjunto estrutural do viaduto alcançasse maiores resistências e durabilidade. $O$ revestimento de concreto armado, aumentando também o seu cobrimento, melhora a resistência e o desempenho da estrutura, o reforço transversal com engrossamento dos pilares melhora a resistência ao cisalhamento. A solução de demolição parcial da estrutura tombada, que foi tomada pelo grupo de trabalho do Viaduto sobre a Galeria dos Estados, se tornou a mais viável, sob o ponto de vista de segurança publica, preservação do patrimônio moderno de Brasília ao longo do efeito do tempo, linguagem arquitetônica modernista e situação orçamentária. O que deve guiar a intervenção é, portanto, um juízo crítico de valor, ideia presente já no pensamento da Carta de Veneza de 1964. A autenticidade do Viaduto sobre a Galeria dos Estados, associada à verdadeira obra de arte da criatividade humana do Lúcio Costa, realça a importância desse trecho viário através da história de Brasília e dos brasilienses.

\section{Referências}

ASSOCIAÇÃO BRASILEIRA DE NORMAS TÉCNICAS (ABNT). NBR 6892: Materiais metálicos Ensaio de Tração - Parte 1: Método de ensaio à temperatura ambiente. Rio de Janeiro, 2012.

ASSOCIAÇÃO BRASILEIRA DE NORMAS TÉCNICAS (ABNT). NBR 7680-1: Concreto - Extração, preparo, ensaio e análise de testemunhos de estruturas de concreto - Parte 1: Resistência à compressão axial. Rio de Janeiro, 2015.

ASSOCIAÇÃO BRASILEIRA DE NORMAS TÉCNICAS (ABNT). NBR 15.575 - Partes 1-6: Edificações Habitacionais - Desempenho: Requisitos gerais. Rio de Janeiro, 2013.

BARROS, A. P. Estudo exploratório da Sintaxe Espacial como ferramenta de alocação de tráfego. Dissertação de Mestrado. PPGT-UnB, 2006.

BARRIENTOS, M. G. G. Adaptação das Edificações Antigas às Necessidades Atuais. Dissertação de mestrado. Rio de Janeiro: FAU/PROARQ, 2004.

BISPO, Alba Nélida de Mendonça. Dos processos de valoração do patrimônio moderno às práticas de conservação em Brasília: o caso do restauro do Palácio do Planalto, dissertação de mestrado, Rio de Janeiro, 2014.

COSTA, L. Relatório do Plano Piloto. Brasília: GDF, 1991.

DER/DF. Relatório técnico - Proposta de recuperação do Viaduto sobre a Galeria dos Estados. Brasília, 2018. 
FORMISANO, A. e MILANI, G. Seismic Vulnerability Analysis and Retrofitting of the SS. Rosario Church Bell Tower in Finale Emilia (Modena, Italy). Front. Built Environment. 5:70. doi: 10.3389/fbuil.2019.00070, 2019.

HOLANDA, F. O espaço de exceção. Brasília: EDUnB, 2002.

MACDONALD, S. et al. Conservation of modern architecture. Ed. Donhead, Shaftesbury, UK, 2007.

MEDEIROS, V. Urbis Brasiliae. Brasília: EDUnB, 2013.

MINISTRY OF URBAN DEVELOPMENT. The Seismic Retrofitting Guidelines of Buildings in Nepal. Kathmandu, 2016.

MORAES, V. T. F., QUELHAS, O. L. G. O desenvolvimento da metodologia e os processos de um "retrofit" arquitetônico. Brasília: Sistema e gestão. Rio de Janeiro, 2012.

NEGREIROS, I. Retrofit Urbano: uma abordagem para apoio de tomada de decisão. Tese de Doutorado. Escola Politécnica de São Paulo, 2018.

RELATÓRIO TÉCNICO - Dept. ENC/UnB 001. Brasília, 26.02.2018.

RELATÓRIO TÉCNICO - Grupo de trabalho conforme Decreto 38.841 de 06.02.2018. Brasília, 2018.

UEDA, T., SHIMOMURA, T. Guidelines for Retrofit of Concrete Structure - Draft. JSCE, 1999.

UNESCO, 2005. Operational Guidelines for the implementation of the World Heritage Convention. Paris: World Heritage Centre, 2005.

VALE, M. S. Diretrizes para racionalização e atualização das edificações: segundo o conceito da qualidade e sobre ótica do Retrofit. Rio de Janeiro: UFRJ/FAU, 2006. 